\title{
Translating irony into Arabic - who's having the last laugh? Dubbing Monsters Inc.: Egyptian vernacular vs. modern standard Arabic
}

\author{
Rashid Yahiaoui \\ Hamad Bin Khalifa University, Doha/Qatar \\ ryahiaoui@hbku.edu.qa
}

Basema Alqumboz

Hamad Bin Khalifa University, Doha/Qatar

b.abualqumboz1002@education.qa

\author{
Ashraf Fattah \\ Hamad Bin Khalifa University, Doha/Qatar \\ afattah@hbku.edu.qa
}

\section{Amer Al Adwan}

Hamad Bin Khalifa University, Doha/Qatar

aadwan@hbku.edu.qa

\begin{abstract}
Monsters Inc., an animated feature film produced by Pixar Animation Studios in 2001, received significant recognition worldwide. The film was nominated in 2002 for the ASCAP Film and Television Music Awards by the Box Office Films. Two dubbed versions of the film were later released with Arabic translations using Egyptian Vernacular, a spoken dialect, and Modern Standard Arabic, used primarily in formal, written communications. This study examines humor in translation and irony as humor which represents a common technique in "Pixar plotting". The research investigates the strategies, types, and categories of irony as humor within the translations and the success of those translations at accurately transmitting the humorous meaning. Aimed towards exploring the problems of translating irony across languages and cultures, this research examines the shifts in translations between the two Arabic language versions, using an interdisciplinary theoretical approach encompassing humor studies, audiovisual translation studies, and descriptive translation studies. Furthermore, the research adopts Muecke's (1978) classification of irony markers to categorize and identify the strategies used in translating irony as humor. The study finds that the two different versions of Arabic utilize similar strategies at certain times and divergent ones at others.
\end{abstract}


They include explication, substitution, omission or addition, in translating irony as humor, with each strategy succeeding or failing at varied levels of meaning transmission. The research suggests that translators' creativity, or lack thereof, and the language variant used are primarily responsible for the success or failure of transmitting irony as humor for dubbing into Arabic.

Keywords: Audiovisual translation; dubbing; humor translation; irony; MSA; Arabic vernacular

\section{Background}

For the purpose of this research, Monsters Inc. was used as a case study to investigate the translation of irony from English into Modern Standard Arabic (MSA) and Egyptian vernacular (EV). Monsters Inc. was released in 2001 by Disney Pictures as an animated feature film, produced and created by Pixar Animation Studios. It was a film franchise that proved to be a success among children of all ages around the world. In the year of its release, Monsters Inc. was dubbed into the Egyptian vernacular (EV) and enjoyed similar success in international markets. Twelve years later, in 2013, Monsters Inc. was dubbed again, this time into MSA. As one of the most used languages in the world, MSA offered Disney an opportunity to serve the entire Arab world market. However, despite Disney's desire to be more language-inclusive, the MSA-dubbed film received overwhelmingly negative reviews. The less-than-stellar critical responses claimed that the film failed to convey the sense of humor into the MSA version, as compared to the EV one (Monsters Inc. Facebook n.p.).

This study investigates the rendering of irony as humor in Monsters Inc. into Arabic, by contrasting two dubbed versions in EV and MSA. The research explores both Target Texts (TTs) in transcript format to identify examples of irony, in order to determine if they were rendered effectively or lost in translation. Qualitative and quantitative evidence of the translation differences between EV and MSA versions is sought to better understand how irony as humor often fails to translate across heterogeneous languages and cultures. (Turek 2010: 560).

\section{Introduction}

Burman (2016: 88) speaks fondly of translation as "an amazing feat" requiring "an amazing ability to move between two profoundly different languages". His love of translation grew out of an early understanding of the great difficulty involved in relocating one particular intention of meaning through a largely cumbersome process into an entirely different system of meaning (ibid.). Burman considers the process of translation to be "paradoxical to its core," as it is an "attempt to say the same thing but in entirely different words" (ibid.: 92). He asserts that in order to render an adequate and acceptable translation, the process of translation must occur by way of a "profound embrace of another language and culture," with all of its "generic conventions, institutional imperatives, or unspoken cultural taboos" (ibid.: 91-92). To this end, translators undertake the painstaking task of enabling the transmission of ideas from one state of thinking to another. This task is even more challenging when dealing with irony as humor.

Muecke (1978: 366) suggests that "[irony] is something to be savoured, not merely solved". Here, Muecke (ibid.) seems to agree with Burman's (2016) view on translation as an ironical task, which derives pleasure in its output rather than itself. Just like other types of humor, irony depends entirely upon individual wit and the ability to quickly perceive the entirety of a situation. In transferring irony across languages and cultures, reconstructing ironic meaning requires significant effort and care to preserve the metacommunicative function; that is, the commentary which occurs 
between the situation and a larger context. By itself, irony as humor serves as both a comment within the dialogue and a comment upon the act or situation of dialogue itself. Like Burman (2016), who asserts the cumbersome nature of translation, Muecke (1978) prescribes an altogether laissez-faire approach that is less process-oriented and more results-based. In other words, Muecke (ibid.) seems to agree with Burman that translation is a difficult process, with linguistic and cultural barriers being its most common hindrances. However, it is also conceivable to resolve issues of equivalence by resorting to creativity and transcreation. Due to the difficulty of conveying meaning from language to language, scholars like Vandaele (2002), Chiaro (2008), and Von Stackelberg (1988) agree that some linguistic deviation will be observed in all translations.

\section{Translating humor}

Simply put, the primary aim of any translation is to convey the meaning of a text in another language. In this process, there are many factors to determine which aspect(s) of meaning can or should be preserved in translation, which largely depends on the text itself, especially its categorized genre. One helpful guide to understanding the genre of media to be translated incorporates Zabalbeascoa's (1996: 243) "vertical scale of importance". In this scale, there are four prioritizing possibilities for attempting to create the most accurate translation: top, middle, marginal, and prohibited. Top priorities must be achieved at all costs, while prohibited priorities should not appear in the text at all. Within this range, translators have the freedom to determine which instances will be given the greatest care. In the case of humorous discourse, importance is attached to humorous effect, to ensure that humor is conveyed. As such, humor would be one of the examples of a top priority in comedy films. This means that humor in comedies is to be viewed as a goal in itself, and that conveying it must be achieved to attain successful reconstruction (Zabalbeascoa 2005: 201-202). With regard to translating comical writing, Von Stackelberg (1988: 10) differentiates between the two polar opposites: "belles infidèles" [beautiful unfaithful] and "ugly faithfulness". He states that instead of resorting to old, outdated, incompatible criteria, translators should seek to gain balance through "equivalence" vs. "acceptance" (ibid.). This results in a great deal of attention being paid to the receiver of the text or the audience.

A successful translation, then, is not necessarily the literal transmittance of meaning, but one which achieves equivalent effect; in this regard, carrying over amusement related to humor. When watching a comedy, audiences expect to be amused. This is a fair justification for resorting to functional equivalences in translation, even though, at times, this entails a linguistic or cultural deviation through departure from the ST (Chiaro 2009). As with poetry, formal equivalence, or formal correspondence, is sacrificed for the sake of dynamic equivalence, or functional equivalence. This sacrifice tends to result in successful rendering of humorous intent. While some features of humor will always, undoubtedly, be lost in translation, Chiaro (2008) emphasizes that translating humor involves some compensation when dealing with linguistic and cultural problems. Achieving functional equivalence results, to varying degrees, in an adapted translation and leads inevitably to what Venuti (1995) calls a domesticated version of the original, essentially an example of target orientation. It is worth mentioning that maintaining the comical aspect of humorous texts does not grant the translator the freedom to clarify what is left intentionally vague by the original author or to improve on it. Whichever translation strategy adopted for rendering a humorous text, it is important to take the genre into account to ensure that "comical writing remains comical writing in translation just as a tragic text must remain tragic" (Von Stackelberg 1988: 12-13). This is an important aspect to emphasize as the successful rendering of humor should not supersede the functional integrity of the original text and the purpose of translation. 


\subsection{Irony as humor}

The concept of irony is quite an elusive one, as it intertwines with other areas of humor, such as satire and sarcasm. The classic definition views irony as saying something while meaning the opposite; therefore, it is incumbent on the receiver to interpret appropriately the attitudinal intention of the speaker for the irony to be carried successfully. This disparity between what is perceived and what is real propels the most common definitions of irony as a humorous tool. For instance, according to the Oxford English Dictionary, irony is "the expression of one's meaning by using language that normally signifies the opposite, typically for humorous or emphatic effect". This definition addresses the verbal aspect of irony, which is merely one component of irony as humor. There are many classifications of irony. The New Princeton Online Encyclopedia of Poetry and Poetics identifies seven types: classical, romantic, tragic, cosmic, verbal, dramatic, and poetic irony. The most common distinction, nevertheless, is usually made between three types: verbal, situational, and dramatic. The three types are usually distinguished by the fact that a) verbal irony operates on the level of words which are used intentionally to serve an ironical purpose, b) dramatic irony takes place when the audience is made aware of things the character is not, and c) situational irony occurs when there is a discrepancy between what is expected to happen and what actually happens (Kreuz and Roberts 1993). It is the verbal irony, where meaning is concealed, that presents the most significant challenges for translators, but it can still be translated "provided that the relevant words have straight one-to-one TL equivalents, and the SL and TL readerships have similar cultural and educational backgrounds" (Newmark 1993: 132). Essentially, the greater lexical equivalence the TL and the SL share, the more likely irony as humor will translate across languages. Consequently, this will determine what strategies to employ.

\subsection{Irony in audiovisual context}

Irony in filmic and audiovisual contexts presents similar characteristics to any literary and nonliterary contexts; however, in the former, the visual and acoustic channels are the main conduit of irony. According to Delabastita (1989: 199), there are four variables in which irony can be expressed:

1) Visual presentation - verbal signs, i.e. irony has a visual component which presents a verbal element (writing on shots for example).

2) Visual presentation - nonverbal signs, i.e. irony is dependent on visual elements only.

3) Acoustic presentation - verbal signs, i.e. irony is based on verbal expressions.

4) Acoustic presentation - non-verbal signs, i.e. irony is carried through non-verbal elements; however, it is perceptible via auditory channel (noises, diegetic sounds, music etc.).

What is worth noting is that, despite the density of the dialogue (verbal elements), it is the situational irony that is most prevalent in Monsters Inc. This type of irony, as Kierkegaard (1966: 271-272) argues, is "not present in nature for one who is too natural and too naïve, but only exhibits itself for one who is himself ironically developed... To become conscious of this requires a consciousness which is itself ironical". This suggests that the receiver/audience has to possess a sense of irony in order to perceive situational irony.

In audiovisual translation, especially subtitling and dubbing, transferring irony is even more challenging given that translators need to abide by certain linguistic and technical constraints (Spanakaki 2007). In dubbing humor into Persian, for instance, Jabbari and Ravizi (2012) argue that no single specific strategy is employed by translators, nor is one suggested for translation. However, the analysis of various dubbed ironies into Persian reveals that translators adopted three main strategies: literal translation, omission and free translation. Jabbari and Ravizi also point out that the 
analysis of ten American animations dubbed into Persian revealed that the number of humorous instances increased in the target text, and consequently offered the target audience a successful and more humorous version of the original. This is certainly not the case in the subtitling of various humor devices identified in the American sitcom Two and a Half Men into Arabic. Al-Adwan and Yahiaoui (2018: 98) argue that humor is often lost or manipulated, pointing out that "there is often a clash between the Arabic subtitles displayed on-screen and canned laughter in the background, as well as the facial expressions of the characters that are usually used to trigger and signal humorous instances".

Scouring the literature of studies on translating humor into Arabic yields meagre results. To the best of our knowledge, no previous studies have shown that MSA is more successful than EV in communicating the intended humour triggered by various types of irony, especially in the genre of animated shows. Furthermore, no contrastive analysis comparing dubbing and subtitling of this genre has been conducted in Arabic. The current study argues, based on the analysis, that EV has been more fluid in terms of transferring the linguistic and humorous aspects of the original dialogue. This claim is further supported by Abomoati (2018), who examines the strategies used in dubbing humour in the American series Fuller House into EV. In her analysis of various instances of language-based and reference-based humour, she asserts that "a dialect would be better than the formal language variety for successfully translating the humorous effect" (ibid.: 7). In a similar study that examined the Arabic subtitling of satire in the American series Seinfeld, Alharthi points out that Arab subtitlers faced difficulties translating most of the culture-based satire. He further argues that subtitling these instances into MSA "was a problematic issue, forcing the subtitler to retain all cultural references in the target text (TT) without any modifications, resulting in humourless subtitles" (ibid.: 22).

\subsection{Irony markers}

In addition to the types of irony, various scholars have identified many different types of irony markers that a comedian or ironist can use to form jokes or humorous situations. This study is mainly concerned with manifest codified markers. As such, this research will identify instances of irony based on the markers recognized by Muecke (1969) who provided another triplicate classification. Based on his classification, a situation is ironical if contradiction is set up between text and context, text and co-text, or text and text. The first is based on shared knowledge between the addresser and addressee. The second relies on verbal context to oppose two parts of the text. The third is based on linguistic features of the text itself. Markers in the third category which will be the focus of this research are classified into kinesic, graphic, phonic, lexical, and discourse markers. Kinesic relates to gestures. Graphic relates to physical representations. Phonic relates to the use of sounds, tones, or words. Lexical relates to the use of advanced diction. And discourse markers relate to the use of interrupters or verbal intonations as nonverbal communications.

\section{Monsters Inc.}

Monsters Inc. is set in a fictional world based on the irrational, childish fear that monsters are hiding inside our closets or under our beds. Every child has developed a fear of monsters, usually from monsters seen on screen. These invisible creatures are just waiting for us to go asleep in order to enter our rooms and scare us to death. In the film, there are two worlds: Monstropolis, the world where the monsters live, and the human world, the place where human beings live. The two worlds are separated by portals represented by closet doors in the children's rooms. Meanwhile, Monsters Incorporated is a utility company in Monstropolis that provides energy to the entire city by collecting children's screams. Monsters of all shapes and sizes emerge at night from children's closets to scare them and collect their screams in canisters to power the monster city. This feature of the plot adds in the element 
of real-world business and economic infrastructures. According to the company's scare record, a character named Sullivan is the top scarer, and Mike, a secondary character, is his assistant. The plot of the film starts rising when Randall, Sullivan's rival, tries to break the record by cheating and attempting to gain unauthorized overtime. Accidently, Sullivan discovers the closet door, and upon opening it to explore it further, permits a human child to enter the monster world. Unfortunately, Sullivan seems incapable of putting the child, a toddler girl who calls him Kitty, back through the door without being discovered by other scarers. So, he is forced to kidnap the little girl and hide her until he can return her safely into her designated closet door portal. The rest of the film is centered on the different ideas Sullivan and Mike devise to return the little girl they call Boo to the human world. Of course, the trio are thwarted at every turn and face a perceived total loss of their objective. Nevertheless, the movie ends successfully with Sullivan managing to return Boo to her home whilst defeating his unexpected nemesis.

It should be stated that the most significant irony of Monsters Inc. is embedded in the very concept of Monstropolis and Monsters Incorporated: the monsters are afraid of children! Despite working in a job deemed hazardous and requiring a fierce ability to inspire fear, the monsters possess an exaggerated fear of children which belies their role as scarers. Even mere contact with a child's toys causes a hysterical frenzy amongst the monsters.

\title{
5. Data analysis
}

Twenty instances of irony were identified in the film. However, in order to prevent an oversaturation of examples within the research, the excerpts selected for analysis reflect various types of irony and irony markers. To preserve the sequential flow of the plot, necessary for understanding, the chronological order of the examples is maintained based on the order of their appearance in the film. Additionally, all English transcripts were retrieved from the film's screenplay. The time codes are based on those shown in the original film version.

Table 1. Example 1

\author{
Time: (2:36) \\ Context: A dragon-like monster, Flint, is evaluating Bile's performance and explaining the mistake he \\ has made during the simulation. \\ Type of Irony: verbal and situational \\ Irony marker: text to text, text to co-text, kinesic (facial gestures)

\section{Source Text:} \\ Flint: Alright, Mr... Bile, is it? \\ Bile: Uh, my friends call me Phlegm. \\ Flint: Uh huh, Mr. Bile, can you tell me what you did wrong? \\ Bile: I fell down? \\ Flint: No, no, before that! Can anyone tell me Mr. Bile's big mistake? Anyone? Let's take a look at the \\ tape. Here we go. Right... there! See? The door. You left it wide open.
}

\begin{tabular}{|l|l|}
\hline Target text (EV) & Back translation \\
\hline فلت: اسمك فتح الباب، مش كدة؟ & Flit: Your name is Open Door, is it? \\
& Fathi: Uh, my friends call me the \\
& فتحي: أصحابي بينادوني فتحي. \\
\hline
\end{tabular}




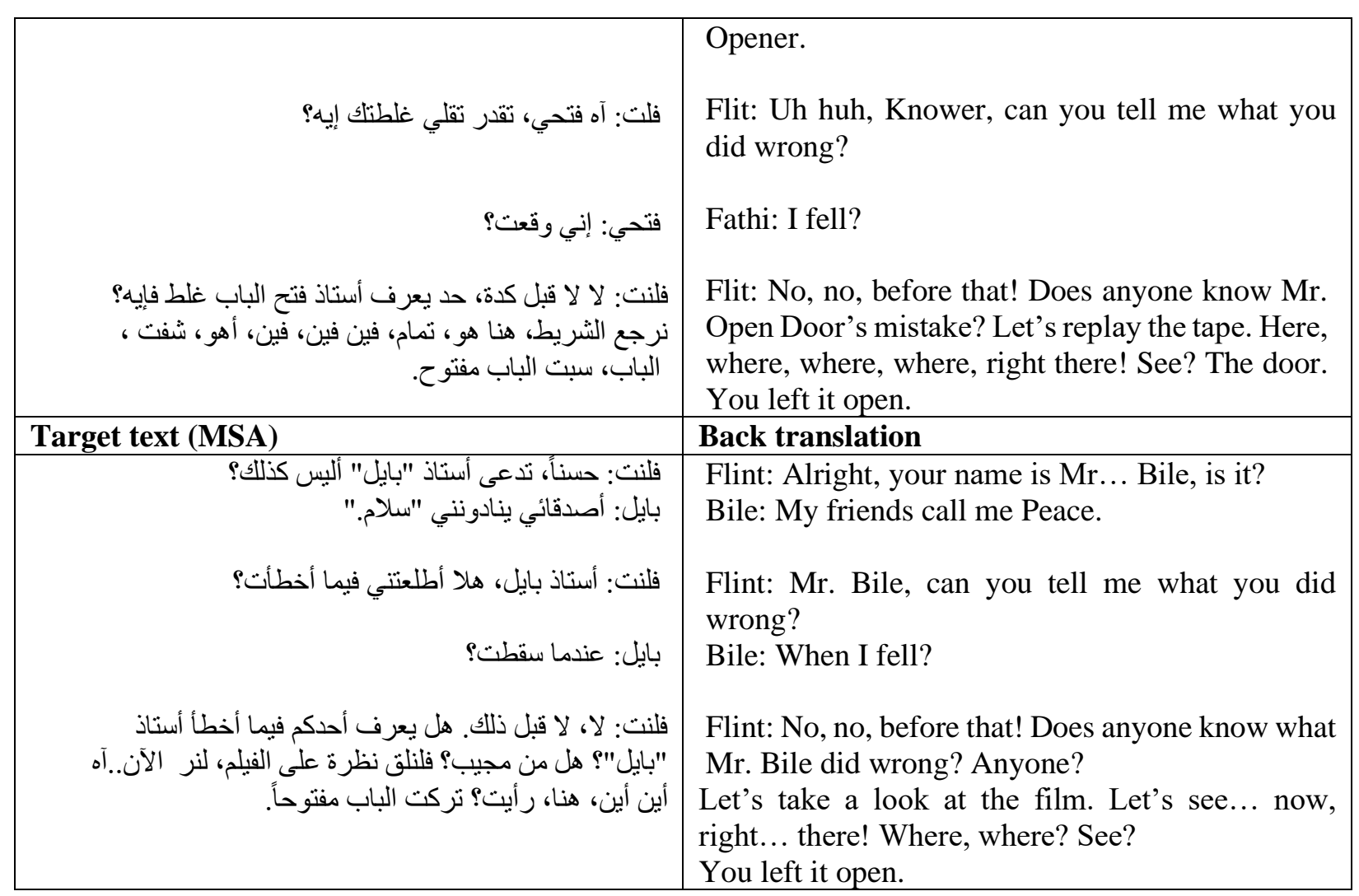

The film opens with an image of a little boy lying in bed as his parents' footsteps fade away down the hall. A monster, Bile, then sneaks into the room from the closet ready to scare the child. But when the child gets up screaming, Bile takes fright and hurriedly steps back from the bed, tripping over a football and a skateboard before landing painfully and comically on his backside and a bunch of jacks on the floor. With Bile thus failing to scare the child, and ending up looking more scared than the child, the whole scene is revealed to be a simulation lesson where beginner monsters are tested for their scare tactics. This situational irony of a cowardly, clumsy, naïve-looking monster getting scared by the screams of a child he is meant to scare is comically accentuated by the incongruity of the character's name, Bile (implying anger, bitterness and irritability), and his naive remark, "My friends call me Phlegm" (reflecting his calm temperament). This ironic contrast between what occurred and what was expected to occur is much more pronounced in the EV version thanks to the strategy of transcreating names or "chunking sideways", to use Chiaro's (2009) term, i.e. replacing one cultural term with another that is neither more general nor more specific. Thus, Bile is given the relevant culturally appropriate proper noun Fathi (literally "concerned/to do with opening") or the nickname Fath Albab (literally "opening the door"), which brings the overall situational irony into further relief by creating another humorous opposition between a character's name (opening doors) and its expected behavior in the situation (closing doors).

In contrast, the MSA version opts for transliterating English names, an "overt" translation strategy in accordance with House (1981) that neither seeks to capture the ironic humorous contrast between "Bile" and "Phlegm", nor enhance the involved situational irony. As an exception to this strategy, the MSA translator sought to provide a semantically relevant Arabic counterpart for "Phlegm", namely Salam (peace), which may reflect a comparable temperament but fails to bring out any contrast with the transliterated equivalent of "Bile". Thus, while proper nouns contribute to the constructed ironic situation in both the ST and the EV versions, they are neutralized in the MSA version, thereby detracting from the intended humorous effect. 
Both EV and MSA versions successfully mimic the incongruity of the character's voice, which betokens naivety, obtuseness and diffidence, thereby enhancing the situational irony.

Table 2. Example 2

\begin{tabular}{|c|c|}
\hline $\begin{array}{l}\text { Time: (3:51) } \\
\text { Context: Mr. Waternoose, CEO of Monsters Inc., s } \\
\text { Type of Irony: situational } \\
\text { Irony marker: Kinesic (sleep), phonic (snorin } \\
\text { dissimulation). }\end{array}$ & $\begin{array}{l}\text { teps from the shadows and talks to the rookies. } \\
\text { g), linguistic (repetition, strong adjectives, over }\end{array}$ \\
\hline $\begin{array}{l}\text { Source Text: } \\
\text { Waternoose: Our city is counting on you to collect } \\
\text { why I need you to be at your best. I need Scarers wl } \\
\text { Tenacious. Tough! Intimidating! I need Scarers like }\end{array}$ & $\begin{array}{l}\text { screams. }[\ldots] \text { Yes, it's dangerous work, and that's } \\
\text { o are confident. } \\
\text {.. like... James P. Sullivan! }\end{array}$ \\
\hline Target text (EV) & Back translation \\
\hline 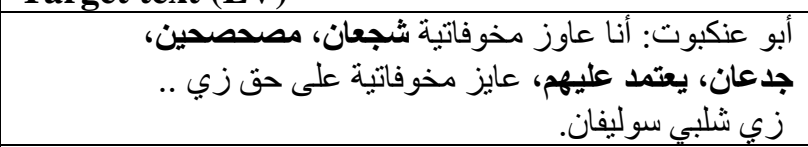 & $\begin{array}{l}\text { Father of Spider: I need scarers who are brave, } \\
\text { wide-awake, tough, reliable. I need real scarer } \\
\text { like Shalabi Sullivan. }\end{array}$ \\
\hline Target text (MSA) & Back translation \\
\hline 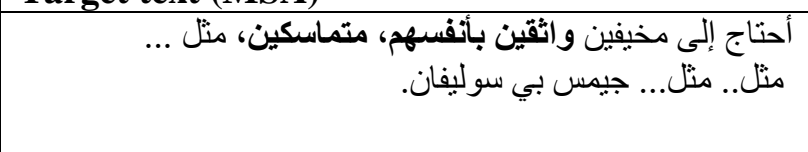 & $\begin{array}{l}\text { I need scarers who are confident, tenacious, like... } \\
\text { like... like.. James B. } \\
\text { Sullivan. }\end{array}$ \\
\hline
\end{tabular}

In this second example, Mr. Waternoose lists four essential qualities of ideal scarers, i.e. "confident, tenacious, tough and intimidating", which he claims to be epitomized by the monster James P. Sullivan. Such a description serves to build up the viewer's expectation of what Sullivan would look like, conjuring up the image of a tough, scary monster. This expectation is intensified by lexical elements such as "at your best" and the repetition of "scarers" and "like", with a pause between the two occurrences of "like" creating an added sense of irony through the use of suspense. However, this scene is juxtaposed to the following one, in which Sullivan, the supposedly model scarer, is seen snoring loudly, still in bed and fast asleep. Thus, the expectation built up by Waternoose's verbal description is soon frustrated or invalidated (Lucariello 1994; Muecke 1969) by the incongruous kinesic and phonic elements of the following scene.

In the EV version, the translation succeeded in preserving or even accentuating the intended humorous situational irony by providing four epithets, which are functionally adequate, though not necessarily accurate lexical equivalents: "brave, wide-awake, tough and reliable." Of particular importance here is the humorous epithet مصحصحين (wide-awake), which is in sharp contrast with Sullivan snoring in the next scene. In other words, the EV translator sought to capture and intensify the irony involved, rather than aiming for some pointless literal equivalence. But the effectiveness of the EV version is also attributable in no small measure to its colloquial register, where naturally humorous words are cleverly selected to create the situational irony, namely مخوفاتية (scarers);

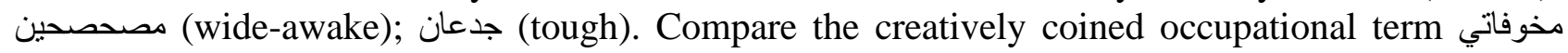
(scarer) in the EV version with the rather flat (ones who scare) in the MSA version. A further manifestation of this strategy of intensification is repetition with intensive qualification: "I need scarers proper...".

In contrast, the translator of the MSA version provides an inaccurate deflated rendering of the four epithets of scarers, which are meant to contrast with the ensuing scene. Only two restrained 
epithets are provided: "self-confident" and "tenacious," without any repetition or intensification. Indeed, due to the omission of some of the epithets in the ST, for a moment, the audible words in the MSA version do not seem to match the lip movements of the character.

Table 3. Example 3

\section{Time: (20:33)}

Context: Mike is telling Sullivan how much he admires Celia. By the moment he turns he is surprised to see Roz instead.

Type of Irony: situational, verbal

Irony marker: text to co-text, text to context, phonic, kinesic

\section{Source Text:}

Mike: I gotta tell you buddy that face of hers... it just makes my heart go...Yikes!

Roz: Hello, Wazowski. Fun filled evening planned for tonight?

Mike: Well, as a matter of fact

Roz: And I'm sure you filled your paperwork correctly. For once.

Roz: Your stunned silence is very reassuring.

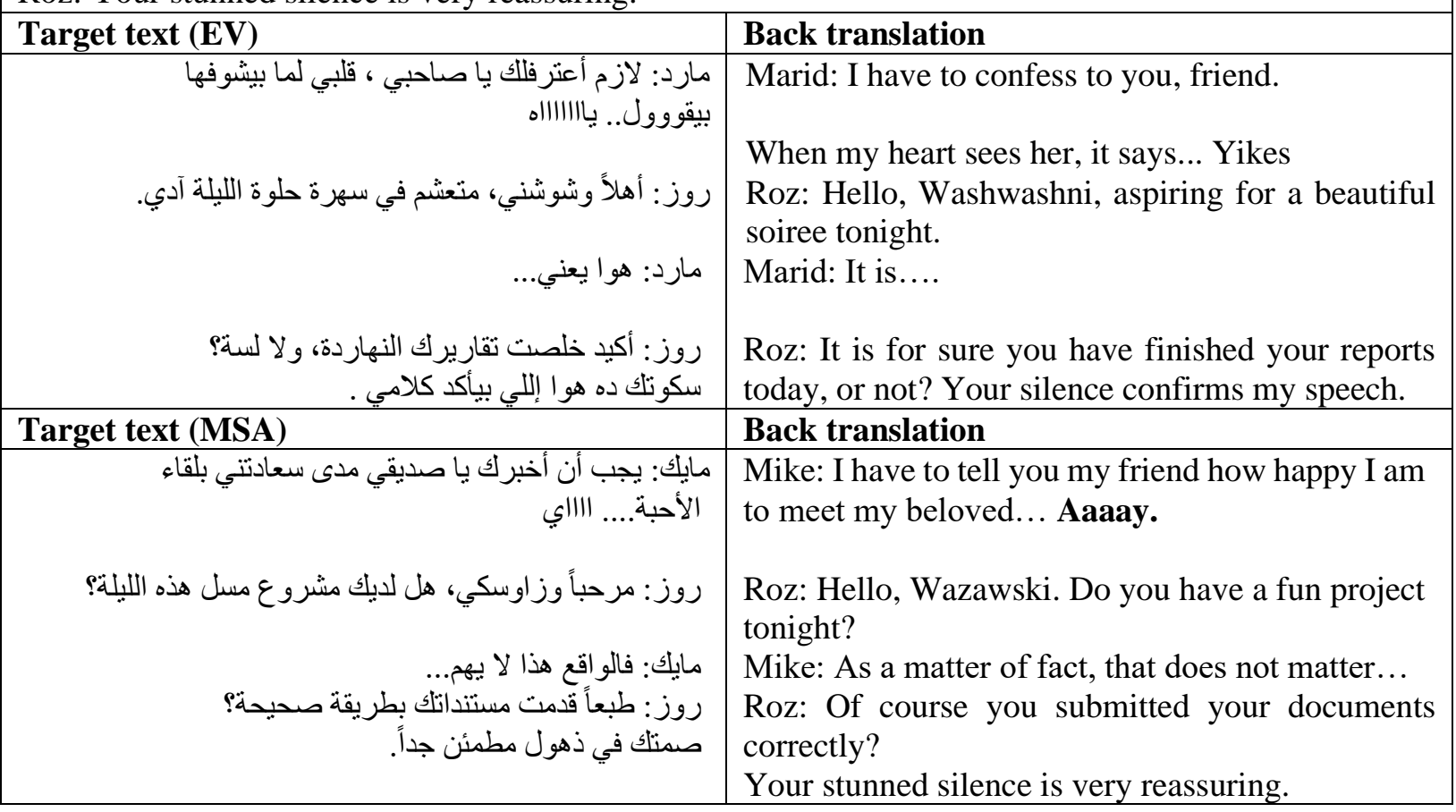

This instance of irony actually contains three different types of irony: two situational and one verbal. The word "yikes," used to express surprise and fear, is rendered accurately in the TTs, but in a higher pitch in the EV. Roz is asking Mike whether he has filed his paperwork "correctly," a word that contradicts what will happen later when Sullivan is going to shuffle through Mike's scare reports. This type of irony is missed in the EV and maintained in MSA through a literal translation, "Of course you submitted your documents correctly?" In this case, Roz's utterance, "Your stunned silence is very reassuring," is an antiphrasis said in a very flat tone, a phonological irony marker that directs the viewer to interpret her message ironically. "Stunned" and "reassuring" are strong adjectives used to strengthen the effect of the irony in her words as being different in meaning from what is stated. The use of "very" to modify "reassuring" adds even more emphasis to the adjective. 
On the grounds that Roz and the viewer know it is a custom of Mike to be lazy when filing his paperwork, and as he has wished in a previous scene "to just let them blow away," using these overestimating adjectives is a deliberate hint as to the real nature of the ironic message. The blank face Mike turns to Roz further supports the ironic implied meaning that he has not done his paperwork after all. In translation, "correctly" and "for once" are omitted in EV. The word "stunned" is also omitted. However, "reassuring" is maintained. In MSA, "for once" is also omitted, while the last sentence is literally translated, preserving all the words of the original.

Table 4. Example 4

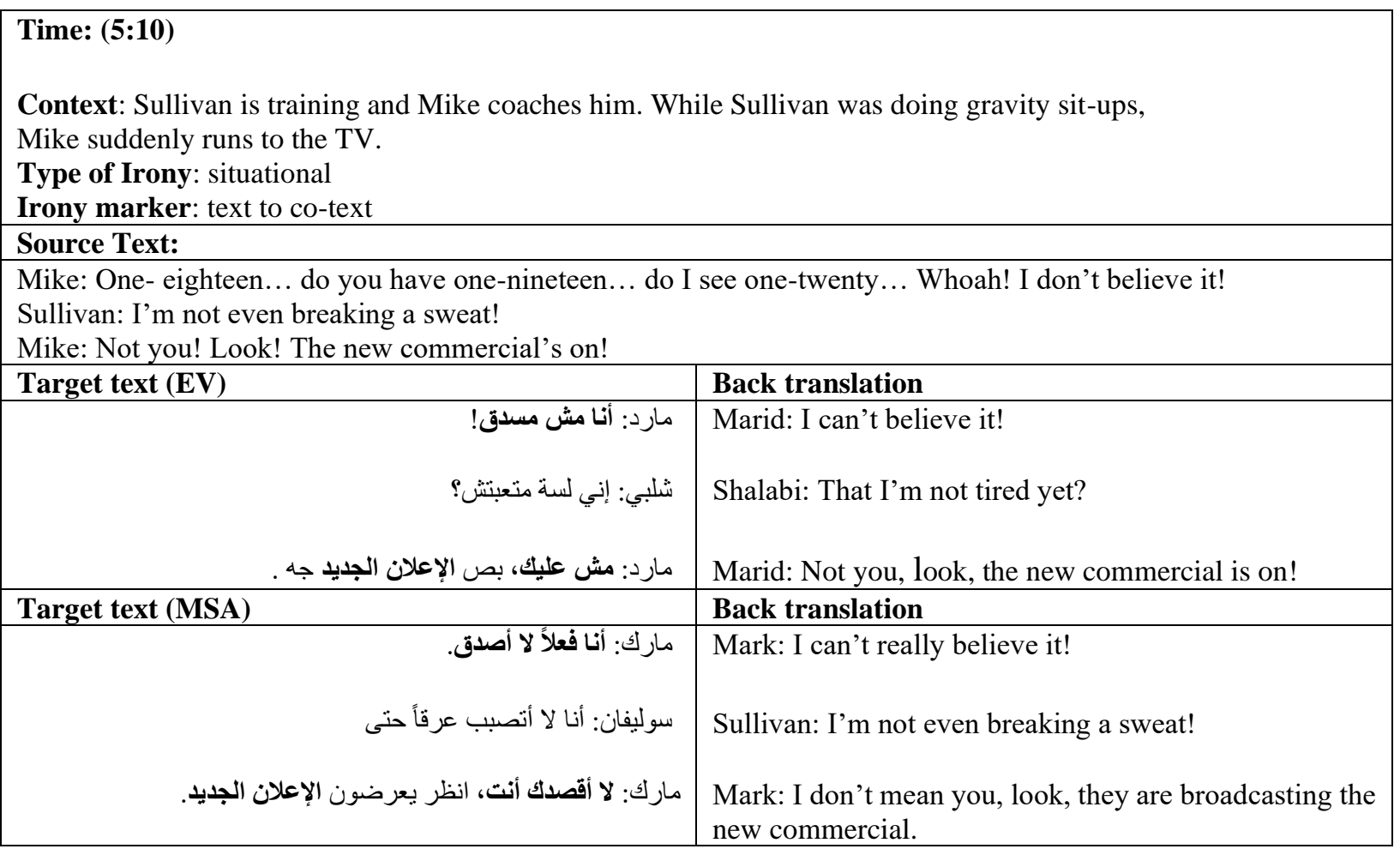

In this third example, Sullivan and the viewer are made to believe that Mike is expressing his disbelief that Sullivan could exercise so profusely and not break a sweat. However, the viewer soon realizes that Mike's words are not in reference to Mike at all, but are actually in response to a television commercial that he will be starring in. Using a discourse marker such as "whoa", which is "present in speech to support interaction but [does] not generally add any specific meaning to the message" (Romero-Trillo 2012, 4916), is accompanied with Mike's facial gestures, opened jaw, body movements, and flailing arms. As such, omitting "whoa", as a discourse marker in both translations does not affect the meaning or impact the translation of irony across the dialects. What matters most is his wording, "I can't believe it," which is then followed with "I don't mean you." The first utterance is translated literally through negation in the EV and MSA. In the EV, the translation renders it "That I am not tired?" This non-interrogative makes it clear that the characters are questioning expectations. Additionally, the MSA stays similar to the original by opting for negation and idiomatically expressing effortlessness with "I'm not even breaking a sweat!" In this way, chunking sideways is once again used, by substituting a relatable target idiom on the same level or with the same intent. In this example, both versions succeed in showing the irony, but the EV uses omission and the MSA uses substitution. 
Table 5. Example 5

\section{Time: (4:08)}

Context: While Sullivan is lying in bed snoring with his alarm clock clicking, Mike is standing next to Sullivan's bed and impersonating a radio announcer in a mocking voice.

Type of Irony: Verbal and situational

Irony marker: Kinesic (sleep; facial expressions; gestures), phonic (snoring; mocking tone of voice), linguistic (contrastive intensification).

\begin{tabular}{|c|c|}
\hline Text: & \\
\hline $\begin{array}{l}\text { Mike: Hey, good morning Monstropolis, it's n } \\
\text { Monster City. Temperature's a balmy } 65 \text { degre } \\
\text { looks like it's gonna be a perfect day to just } \\
\text { THAT FLAB THAT'S HANGING OVER TH }\end{array}$ & $\begin{array}{l}\text { W five after the hour of six a.m. in the big } \\
\text { es, which is good news for you reptiles, and it } \\
\text { ie in bed, sleep in, or simply... WORK OUT } \\
\text { BED!! Get up, Sulley! }\end{array}$ \\
\hline Target text (EV) & Back translation \\
\hline 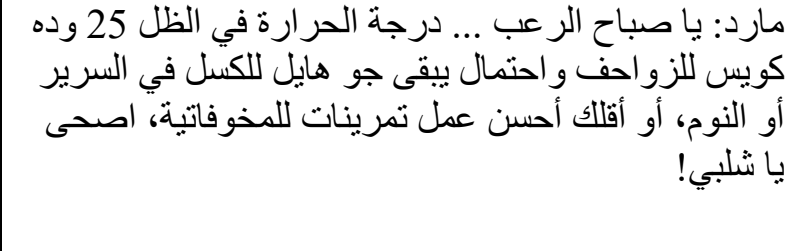 & $\begin{array}{l}\text { Marid: Morning of horror!... Shade } \\
\text { temperature is } 25 \text { degrees, which is good for } \\
\text { reptiles and could be terrific weather for } \\
\text { lazing in bed or sleeping, or better still, for } \\
\text { some workout for scarers! Get up, Shalabi! }\end{array}$ \\
\hline Target text (MSA) & Back translation \\
\hline 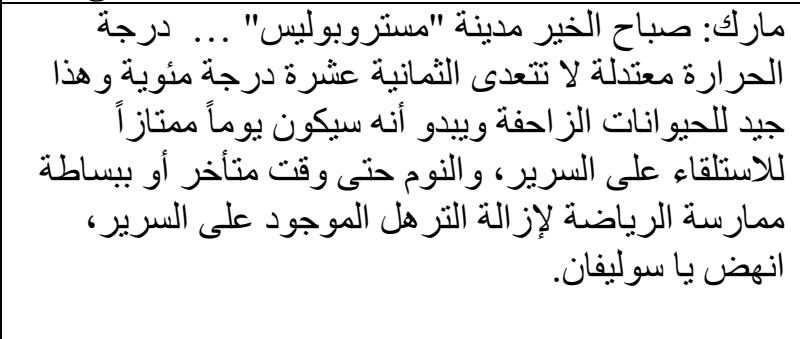 & $\begin{array}{l}\text { Mark: good morning Monstropolis! ... } \\
\text { Temperature is moderate, not exceeding } 18 \\
\text { degrees, which is good for reptilian animals } \\
\text { and it seems it will be a perfect day for } \\
\text { lying in bed and sleeping in, or simply } \\
\text { practising some sport to get rid of the flab } \\
\text { situated in the bed! Get up, Sullivan. }\end{array}$ \\
\hline
\end{tabular}

In this example, we find verbal irony in the ST clause, "it looks like it's gonna be a perfect day to just lie in bed, sleep in...", where Mike is clearly mocking Sullivan for sleeping in, implying that he is lazy and unfit, and should rather get up and exercise. Departing from literal equivalence to accentuate the intended irony, the EV translator resorts to intensification ("terrific weather") and underdissimulation ("lazing in bed"). This under-dissimulation is further reinforced by Mike's facial expressions, gestures and intonation, but it is easily perceivable in the script alone. Intertextuality is also employed in the EV version to achieve a humorous effect; for example, "good morning Monstropolis" is rendered as "the morning of horror," which is modelled on the customary Arabic greeting "morning of goodness" (good morning). There is a sense of irony involved here too with the contrast between the pretended negative meaning (horror reigning over the city) and the real positive one (more and more horror and screams being generated for the benefit of the city).

The MSA rendering, though much closer to the ST, fails to match the kinesic and phonic markers of the verbal irony, as can be demonstrated by reading the script in isolation from the picture; one can easily miss the intended verbal irony because of the matter-of-fact wording and tone typical of a factual description. The mocking tone is only abruptly adopted in the last part of the sentence, "or simply practising sport to get rid of the flab situated on the bed!." 
Table 6. Example 6

\begin{tabular}{|c|c|}
\hline \multicolumn{2}{|c|}{$\begin{array}{l}\text { Time: (6:45) } \\
\text { Context: Mike and Sullivan are heading to work. Mike brags about being seen on TV more often. } \\
\text { Type of Irony: verbal } \\
\text { Irony marker: parody, phonic, kinesic, text to Context }\end{array}$} \\
\hline \multicolumn{2}{|c|}{ Source Text: } \\
\hline \multicolumn{2}{|c|}{$\begin{array}{l}\text { Mike: I'm telling you big daddy, you're going to be seeing this face on T.V. a lot more often. } \\
\text { Sullivan: Yeah? Like on “Monstropolis' Most Wanted”? } \\
\text { Mike: ha, ha, ha. You've been jealous of my good looks since the fourth grade, pal. }\end{array}$} \\
\hline Target text (EV) & Back translation \\
\hline 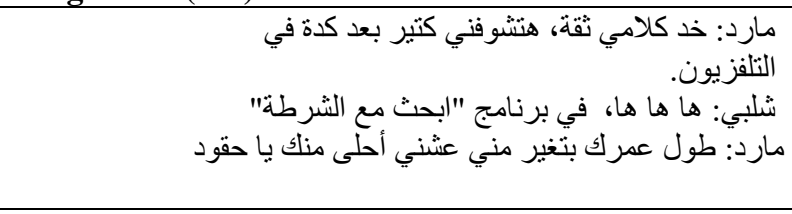 & $\begin{array}{l}\text { Marid: Trust my words, after this you'll be seeing me a } \\
\text { lot more often on TV. } \\
\text { Shalabi: hhhh in "Search with the Police". } \\
\text { Marid: You've always been jealous of me because I am } \\
\text { more handsome than you. }\end{array}$ \\
\hline Target text (MSA) & Back translation \\
\hline 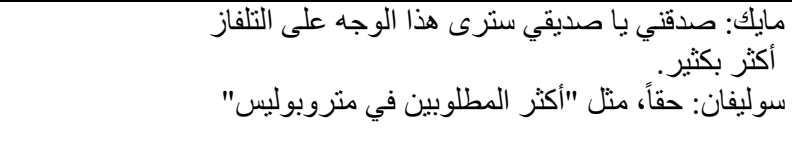 & $\begin{array}{l}\text { Mike: Believe me friend, you will be seeing this face on } \\
\text { TV more often. } \\
\text { Sullivan: Really, like "Monstropolis' } \\
\text { Most Wanted"? }\end{array}$ \\
\hline مايك: ها ها ها، أنت تغار من وسامتي منذ الصف الر ابع & $\begin{array}{l}\text { Mike: ha, ha, ha. You have been jealous of my good } \\
\text { look since the fourth grade. }\end{array}$ \\
\hline
\end{tabular}

This example uses parody as a type of irony, by alluding to the name of a famous comic TV series and creating a contradiction between being on TV for fame, as Mike believes, and shame, as shown by Sullivan's use of the parody. Here, parody is being used as a device to express ironical disbelief. Unlike the translator of the MSA version, the EV translator does not opt for a literal translation of the name of the show, which would fail to function as an ironic parody. Rather, the EV translator provides a cultural equivalent, namely the name of a similar Egyptian TV show, "Search with the Police," which is a popular hidden camera series starring the Egyptian comedian Ibrahim Nassr. It was popular in the nineties on Egyptian television and on MBC, a famous broadcasting network in the Arab world. Thus, the translation of "Monstropolis' Most Wanted" was achieved again through chunking sideways by providing a culturally specific substitute on the same level, thereby maintaining the irony created through the parody.

In the MSA version, however, this parody is translated literally. But, notwithstanding the concomitant paralinguistic markers of irony, the intended parody is much less accessible to the hearer given the absence of a culturally befitting equivalent. What makes the MSA dubbed rendering even more opaque, and arguably less ironic or humorous, is the subtle propositional shift from a rhetorical question "Like on 'Monstropolis' Most Wanted'?" to a statement "Like the most wanted in Monstropolis." Thus, there is no reference to a show in the MSA rendering, but rather an analogy with the "most wanted" in Monstropolis. The literal rendering of "most wanted" أكثر المطلوبين, has a hint of translationese, which arguably detracts from its humorous ironic effect.

Another overall contrasting feature between the two versions, which has direct bearing on their respective effectiveness in capturing the humorous irony of the ST, is related to the natural contextsensitive variation of register that is remarkable in the EV version. An example of this registerial variation can be found in the immediately preceding scene featuring the Monsters Inc. TV commercial. Here, as would be expected in this kind of genre, the main part of the script is read out by the announcer in MSA, which is interspersed with soundbites in EV. Arguably, this natural 
variation of register enhances the credibility, hence effectiveness, of the EV, unlike its MSA counterpart, which is rather bizarrely mono-registerial (almost uniformly MSA), and hence, unnatural. The overall functional translation strategy of the EV translator, as opposed to the predominantly literal strategy of the MSA translator, can best be illustrated by their respective renderings of the commercial's ironic slogan: "We scare because we care!" While the EV translator cleverly opts for a rhyming, funny, functionally equivalent slogan: يا مخوفاتي نور حياتي (Oh, scarer, نخيف : enlighten my life!), the MSA translator opts for a literal, non-rhyming, ineffectual rendering لأننا نهتم (we scare because we care).

Clearly, the analysis presented here shows that the general orientation of the MSA version is word-for-word translation that follows the form and syntax of the ST. This approach proved mostly unsuccessful in accurately conveying many of the ironic instances. The EV version, on the other hand, managed to carry the ST irony, and in some instances, even enhanced it by introducing additional markers (as in example four). By opting for a transcreation approach, the translator proved that Arabic vernacular could indeed convey various types of irony by cleverly trans-adapting cultural innuendos, playing on words, and echoing the exaggerated irony by stressing, linguistically and phonetically, the unintended meaning through the use of strong adjectives and varying intonation.

\section{Translation strategies}

Table 7. Strategies used in VE vs. MSA

\begin{tabular}{|l|c|c|}
\hline Strategy & EV & MSA \\
\hline Literal translation & 13 & 16 \\
\hline Explicitation & 5 & 1 \\
\hline Substitution & 5 & 3 \\
\hline Omission & 4 & 2 \\
\hline
\end{tabular}

The analysis presented here has clearly shown that the general orientation of both versions is the literal, word-for-word translation that follows the form and syntax of the ST. This way of translation proved successful, in varying degrees, in conveying many of the ironic instances, since the film's dialogue depends on short, direct interactions between characters. If there is incongruity involved, it could be easily rendered through the translation of single words or with the substitution of other words. This was not the case since most of these words have straight one-to-one TL equivalents and cultural references have not played a major role in constructing irony. The most common strategies used (in Table 7) are omission, substitution, and explicitation. Some of these strategies are more prevalent in the EV translation than the MSA version. It is also worth noting here that exaggerating irony as humor, by stressing the unintended meaning linguistically through the use of strong adjectives and phonetically through varying intonation, was intensively employed in the original. This was reflected more in the EV version than in the MSA one. A plausible explanation for this is the nature of the EV, which is very paralinguistically expressive.

\section{Conclusion}

The aim of this paper was to analyze irony as humor in Monsters Inc., a Disney animation film which was dubbed into Egyptian Vernacular and Modern Standard Arabic. To find whether irony as humor is maintained or lost in the two translations, the study opted for a descriptive, methodological framework. This involved contrasting the source text with the two target texts, by focusing on specific 
segments where irony is present. In identifying those segments, the research used Muecke's (1978) classifications of irony markers. Taking the genre into account, the comparison data revealed that situational and dramatic types of irony are the most frequently used as humor in the film. Based on the recurrent types of irony as humor, translational problems were tackled in two distinct ways in both versions. The first dubbed version in EV adopted a more TT-oriented translation strategy, translating many of the names of narrative value using creative and free translation to carry irony as humor. From Toury's (1995) point of view, it can be considered as an "acceptable" translation since it "embraces the linguistic and cultural values of the target poly-system" (Díaz Cintas 2004: 29). The second dubbed version in MSA is more source oriented. It opted for using literal translation and transliteration to render many of the cultural references, such as names. This has produced the socalled "adequate" translation, by "adhering to the values and referents of the source product" (ibid.: 29). However, it is markedly noticeable that literal renderings resulted in losing the metacommunicative function of almost all instances of irony in MSA.

The results of this comparative study can be used to understand why translators make the choices they do when determining source or target orientation and culturally conscious renderings through the adoption of a given approach (literal vs. transadaptation). With this in mind, future studies could seek to identify other films of different genres dubbed in the two versions of Arabic, so as to isolate specific variables which might lead to one particular translation strategy over another. One limitation of this research is the subjective nature of humor in general, and irony in particular, when they are not straightforward and overt instances.

\section{References}

Abomoati, A, G. (2019). 'Strategies for translating audiovisual humor from English into Arabic'. Critical Studies in Languages and Literature 1 (1), pp. 1-16.

Al-Adwan, A. and Yahiaoui, R. (2018). 'Comedy under Fire: Subtitling two and a half men into Arabic', in Ranzato I. and Zanotti, S. (eds.), Linguistic and Cultural Representation in Audiovisual Translation, London and New York: Routledge, pp. 85-100.

Alharthi, A. (2015). 'Strategies of subtitling satire: a case study of the american sitcom seinfeld, with particular reference to English and Arabic'. Arab World English Journal (AWEJ) 4, pp. 22-41.

Arabic Disney. https://www.facebook.com/PixarMonstersInc/ Web. 30 Mar. 2017.

Burman, T. E. (2016). 'The spacious ironies of translation'. The New Centennial Review 16 (1), pp. 87-92.

Chiaro, D. (2008). 'Verbally expressed humor and translation', in Raskin, V. and Ruch, W. (eds.), The Primer of Humor Research, Berlin: Walter de Gruyter, pp. 569-608.

Chiaro, D. (2009). 'Issues in audiovisual translation', in Munday, J. (ed.), The Routledge Companion to Translation Studies, London: Routledge, pp. 141-165.

De Wilde, J. (2010). 'The analysis of translated literary irony: Some methodological issues'. Linguistica Antverpiensa New Series: Themes in Translation Studies 9, pp. 25-44.

Delabastita, D. (1989). 'Translation and mass-communication: film and TV translation as evidence of cultural dynamics'. Babel 35 (4), pp. 193-218

Díaz Cintas, J. (2004). 'In Search of a theoretical framework for the study of audiovisual translation', in Orero, P. (ed.), Topics in Audiovisual Translation, Amsterdam: John Benjamins, pp. 21-34.

Green, R., Cushman, S., and Cavanagh, C. (eds.). (2012). The Princeton Encyclopedia of Poetry and Poetics. Princeton: Princeton University Press.

House, J. (1981). A Model for Translation Quality Assessment. Tübingen: Narr.

Lucariello, J. (1994). 'Situational irony: A concept of events gone awry'. Journal of Experimental Psychology: General 123 (2), pp. 129-145. 
Jabbari, A.A. \& Ravizi, Z. N. (2012). 'Dubbing verbally expressed humor: An analysis of American animation in Persian context'. International Journal of Humanities and Social Science 5 (2), pp. 263-270.

Kierkegaard, S. (1966). The Concept of Irony, with Constant Reference to Socrates. Bloomington: Indiana University Press.

Kreuz, R.J., and Roberts, R.M. (1993). 'The empirical study of figurative language in literature'. Poetics 22, pp. 151-169.

Muecke, D. (1969). The Compus of Irony. London: Methuen

Muecke, D. (1978). 'Irony markers'. Poetics 7, pp. 363-375.

Newmark, P. (1993). Paragraphs on Translation. Clevedon: Multilingual Matters.

Oxford English Dictionary online. http://www.oed.com

Spanakaki, K. (2007). 'Translation humor for subtitling'. April. Translation Journal 11 (2). Retrieved May 30, 2018 from https://translationjournal.net/journal/40humor.htm.

Toury, G. (1995). Descriptive Translation Studies and Beyond. Amsterdam: John Benjamins.

Turek, S. (2010). 'Foreigners in the margins: English subtitles in 'Inch'Allah dimanche'. The French Review', 83 (1), pp. 560-572.

Vandaele, J. (2002). 'Re-Constructing humour: Meanings and means'. The Translator 8 (2), pp. 149172.

Venuti, L. (1995). The Translator's Invisibility. London/New York: Routledge.

Von Stackelberg, J. (1988). 'Translating comical writing'. Translation Review 28(1), pp.10-14.

Zabalbeascoa, P. (1996). 'Translating jokes for dubbed television situation comedies'. The Translator 2 (2), pp. 235-257.

Zabalbeascoa, P. (2005). 'Humor and translation: An interdiscipline'. Humor 18 (2), pp. 185-207.

\section{Filmography}

Monsters Inc. 2013. Dir. Pete Docter. Perf. John Goodman and Billy Crystal. Buena Vista Home Entertainment. 